\title{
RANCANG BANGUN PENYEARAH TERKENDALI PENUH DAN BCR PADA UPS (UNINTRERRUPTABLE POWER SUPPLY)
}

\author{
Aceng Daud $^{1}$, Iqlima Endah Sariyulianti ${ }^{2}$ \\ Jurusan Teknik Konversi Energi - Politeknik Negeri Bandung \\ e-mail: daud_polban@yahoo.com; iqlima.endahsomantri@rocketmail.com
}

\begin{abstract}
Abstrak
Penyearah terkendali penuh dan BCR (Battery Charge Controller) merupakan perangkat utama dari peralatan UPS (Uninteruptable Power Supply). Penyearah terkendali penuh berfungsi untuk mensuplai tegangan searah kepada BCR, dan BCR berfungsi untuk mengatur pengisian kepada baterai. Pengisian baterai secara paksa pada tegangan konstan dengan arus yang sesuai dengan resistansi baterai akan berdampak kepada penurunan masa hidup baterai, disamping tingginya efek penguapan fluida baterai. Pengendalian tegangan masuk baterai saat pengisian sebagai fungsi tegangan baterai akan mengatur besaran aliran arus pengisian. Pengisian baterai melalui BCR disesuaikan dengan tegangan baterai sehingga BCR dapat mengendalikan dengan penetapan tegangan 13,5 V untuk batas atas (HVD) dan 10,5 V untuk batas bawah (LVD). Berdasarkan hasil pengujian kinerja sistem penyearah terkendali penuh dan BCR pada baterai $12 \mathrm{~V}$ kapasitas $10 \mathrm{Ah}$, menunjukkan bahwa pada tegangan keluaran penyearah terkendali penuh sebesar $12 \mathrm{~V}, \mathrm{BCR}$ dapat melakukan pengisian baterai dalam keaadan kosong selama 220 menit dengan variasi arus dari 2, 5 A sampai 0,2 A.
\end{abstract}

Kata kunci: Penyearah, Pengendalian Pengisian Baterai, BCR, dan Tegangan dan arus pengisian.

\section{PENDAHULUAN}

Perangkat komputer atau elektronik khusus membutuhkan catu daya listrik yang terus menerus. Uninterruptible Power Supply (UPS) merupakan sistem penyedia daya listrik yang mampu memasok tenaga listrik saat diperlukan dalam waktu yang cepat, sehingga dampak kehilangan data dapat dihindari. Komponen utama untuk mendukung kerja UPS adalah sistem penyearah arus listrik sebagai pengisi baterai, sehingga inverter dapat memberikan catu daya listrik bolak-balik saat terjadi kegagalan pasokan daya listrik dari PLN. Umumnya UPS terdiri atas inverter, baterai, pengisi baterai, rangkaian pengendali pengisi baterai, stabilisator, saklar pengalih dan indikator.

Rangkaian pengendali pengisi baterai atau dikenal dengan BCR berfungsi untuk mengendalikan proses pengisian baterai. Saat baterai terisi penuh maka sistem pengendali akan melakukan perintah pemutusan rangkaian pengisian baterai. Secara konvensional, rangkaian penyearah menggunakan diode sistem bridge dan BCR hanya diperlukan sebagai pemutus daya listrik saat tegangan baterai mencapai 12 Volt.

Rancang bangun penyearah terkendali penuh dan BCR bertujuan untuk menghasilkan besaran tegangan yang sesuai kebutuhan dan pengendalian arus sesuai dengan kenaikan tegangan baterai.

\section{METODOLOGI}

Penyearah adalah suatu alat yang digunakan untuk mengubah arus AC menjadi DC. Penyearah terkendali, yaitu penyearah yang menggunakan thyristor sebagai komponen penyearah yang diatur sudut penyalaannya. Tegangan keluaran DC yang dihasilkan dapat diubah sesuai dengan sudut pulsa penyalaan pada gate thyristor yang dibangkitkan secara khusus oleh rangkaian trigger. 


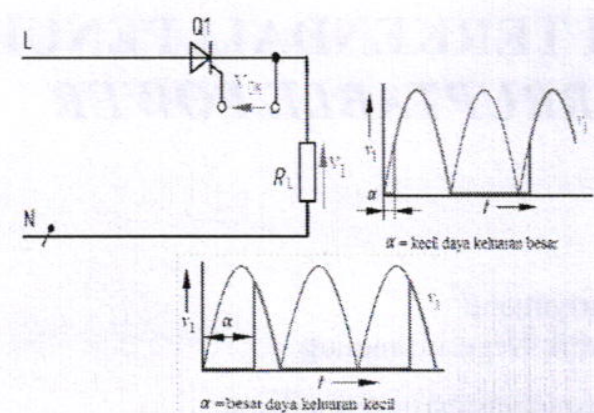

Gambar 1. Penyearah E1C

Gambar 1 menunjukkan prinsip kerja dari penyearah satu-pulsa terkendali. Bila tegangan masukan berupa tegangan sinusoidal dan beban R, maka pada setengah gelombang pertama thyristor mendapat bias-maju. Bila thyristor disulut pada sudut $\alpha$, thyristor Q1 akan konduksi maka tegangan keluaran V1 akan muncul pada beban. Keadaan konduksi ini berlangsung hingga tegangan kembali ke nol dan mulai negatif (komutasi alamiah). Ketika tegangan negatif, maka Q1 dalam keadaan bias-mundur. Waktu dari tegangan mulai beranjak ke arah positif sampai dengan thyristor mulai konduksi disebut sudut penyalaan atau sudut penyulutan $\alpha$. Dengan demikian, tegangan keluaran penyearah dapat diatur-atur dengan mengatur sudut penyalaan pulsa gate-nya, dalam hal ini dari $0^{\circ}-180^{\circ}$. Bila sudut penyalaan $\alpha$ kecil, berarti thyristor konduksi secara dini sehingga tegangan $\left(\mathrm{V}_{\mathrm{d}}\right)$ dan daya keluaran akan besar. Sebaliknya bila sudut $\alpha$ besar, tegangan $\left(\mathrm{V}_{\mathrm{d}}\right)$ dan daya keluarannya akan kecil.

Perbandingan antara tegangan DC yang keluar terhadap tegangan AC yang ikut serta pada hasil output-nya, yang dinamakan factor ripple (riak). Notasi untuk factor ripple adalah $\mathrm{r}$. Besarnya factor ripple dapat dihitung dengan rumus:

$\mathrm{r}=\frac{\text { Komponen } a c}{\text { Komponen } d c} \times 100 \%$

Tegangan keluaran rata-rata DC pada outputnya, dapat dihitung dengan rumus:

$\mathrm{V}_{\mathrm{dc}}=\frac{1}{T} \int V_{\mathrm{o}} \mathrm{t} \mathrm{dt}$

Komponen $\mathrm{AC}$ adalah harga rms dari tegangan AC masukan. Factor ripple dapat dihitung dengan rumus:

$\left.r=\left(\left(\frac{V_{r m s}}{V_{d c}}\right)^{2}-1\right)^{1 / 2}\right) \times 100 \%$ dimana $\mathrm{V}_{\text {rms }}$ merupakan harga rms total dari tegangan output-nya, dapat dihitung dengan rumus :

$\mathrm{V}_{\mathrm{rms}}=\left(\frac{1}{T} \int V m \sin \left(t-30^{\circ}\right) d t\right)^{1 / 2}$

dimana $V_{a v}$ dapat dihitung dengan rumus:

$\mathrm{V}_{\mathrm{av}}=\frac{1}{T} \int V m \sin \left(t-30^{\circ}\right) d t$

$\mathrm{Vm}=\sqrt{2} \mathrm{~V}_{\text {in }}$

Sistem kerja dari penyearah terkendali yaitu dengan memanfaatkan Silicon Control Rectifier (SCR). SCR merupakan salah satu jenis thyristor yang prinsip kerjanya mirip dengan dioda namun dilengkapi gate untuk mengatur besarnya tegangan fasa. SCR adalah komponen semikonduktor yang terbentuk dengan struktur empat lapis PNPN (PositifNegatif-Positif-Negatif) dengan tiga lapisan sambungan PN. SCR memiliki tiga terminal yaitu anoda, katoda dan gate. Sambungan PN ( $P N$ junction) berturut-turut dari anoda diberi simbol J1, J2 dan J3 seperti terlihat pada Gambar 2.

Dari Gambar 2 (a) dapat dipelajari sistem operasi SCR. Apabila tegangan anoda lebih positif dari katoda, sambungan J1 dan J3 pada kondisi forward bias dan $\mathrm{J} 2$ pada kondisi reverse bias. Pada kondisi ini SCR masih dalam kondisi memblokir tegangan maju. Agar arus dapat mengalir dari anoda ke katoda maka diberikan tegangan antara gate terhadap katoda. Jika pada katoda tegangan lebih positif dari anoda, sambungan J2 terbias maju sedangkan J1 dan J3 terbias mundur. Hal ini seperti dioda-dioda yang terhubung seri dengan tegangan balik bagi keduanya. SCR akan berada pada kondisi reverse blocking dan arus bocor reverse (current reverse) akan mengalir melalui device. SCR dapat dihidupkan dengan meningkatkan tegangan maju VAK diatas VBO, tetapi kondisi ini bisa merusak komponen.

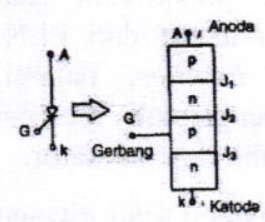

(a)

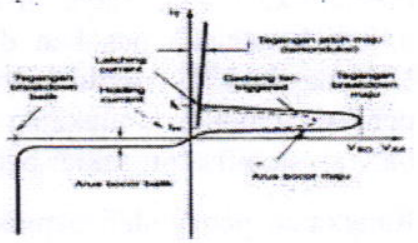

(c)
Gambar 2. Simbol (a), Struktur Fisik (b) dan (c) Karateristik pada SCR (Rashid, 1999)

Metode yang digunakan pada SCR adalah pemicuan melalui gate (pemberian arus gate) yang dilakukan dengan memberi tegangan 
kecil saja pada gate katoda (tergantung spesifikasi produk), maka arus gate dapat mengalir dan membuat kondisi SCR dalam keadaan on. Daerah kerja SCR adalah $0^{\circ}-180^{\circ}$ (sifat umum dioda), maka hanya pada daerah tersebut pengontrolan fasa dapat dilakukan. Apabila SCR telah terpicu, maka SCR berada dalam kondisi menghantarkan arus listrik. Untuk pengaturan fasa atau menghentikan arus listrik maka diperlukan metode komutasi, yaitu mengusahakan tegangan pada SCR adalah nol, sehingga arus tidak mengalir. Pada saat itu dapat dipastikan bahwa SCR dalam kondisi tidak dapat menghantarkan arus listrik dari anoda ke katoda hingga pemicuan dimasukkan kembali.

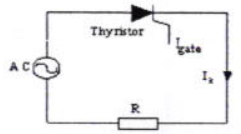

(a)

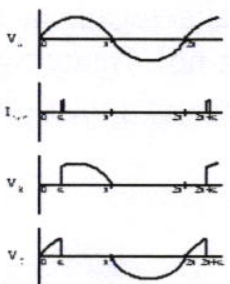

(b)
Gambar 3. (a) Rangkaian Sederhana SCR (b) Bentuk Gelombang Hasil Pemicu SCR (Rashid, 1999)

Gambar 3 (a) menunjukkan rangkaian sederhana SCR dan (b) menunjukkan jika SCR dipicu pada sudut $\alpha^{\circ}$, maka arus akan ditahan dari $0^{\circ}-\alpha^{\circ}$ dan arus akan melewati SCR secara penuh dari $\alpha^{\circ}-180^{\circ}$. Pada $180^{\circ}-360^{\circ}$ SCR akan terbias mundur dan pemicuan tidak akan berguna karena SCR hanya dapat menghantarkan arus jika terbias maju sedangkan apabila terbias mundur SCR akan membloking arus.

Agar diperoleh keluaran tegangan yang sesuai dengan kebutuhan maka diperlukan rangkaian pembangkit sinyal yang dikondisikan pada sudut penyalaan $\alpha^{\circ}$. Rangkaian pembangkit sinyal (pulsa pemicu) untuk konverter satu fasa terdiri dari: (a) Zero crossing detector, (b) integrator, (c) level penggeser, (d) komparator, (e) monostabil, (f) 2 gerbang input AND, (g) astabil multivibrator, (h) penguat pulsa dan (i) transformator pulsa seperti terlihat pada Gambar 4.

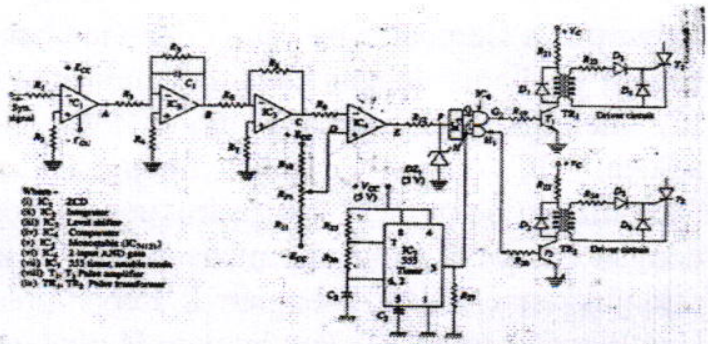

Gambar 4. Rangkaian Pembangkit Sinyal Gerbang (Singh, 1998)

Pada Gambar 4 sinyal sinkronasi secara normal didapat dari sumber yang sama dengan sumber tegangan SCR. Sinyal ini didapatkan dengan menggunakan transformator sinkronasi. Sinyal ini kemudian diberikan kepada IC Zero Crossing Detector (ZCD). Pada IC ZCD ini sinyal kemudian berkembang menjadi gelombang kotak dengan pergeseran fasa $180^{\circ}$ karena kita menggunakan masukan inverter. Tegangan ZCD besarnya +10 volt dari tegangan sumber \pm 12 volt. Sinyal gelombang kotak kemudian digabungkan oleh integrator $\mathrm{IC}_{2} . \mathrm{IC}_{3}$ adalah penggeser level yang menggeser sinyal integrasi dan menghasilkan gelombang seperti yang ditunjukkan Gambar 5 bagian C.

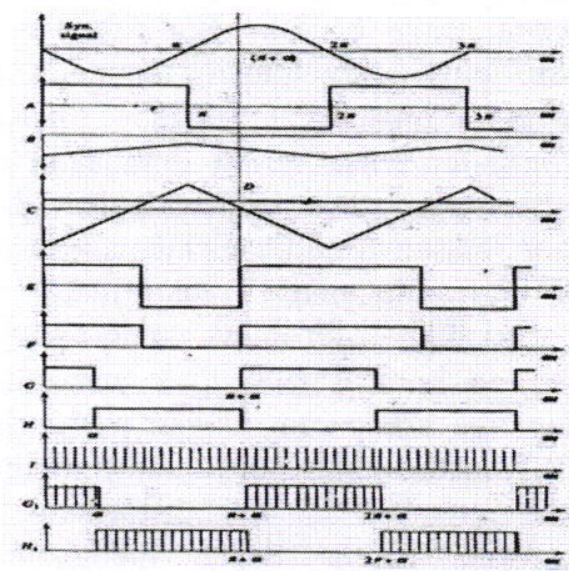

Gambar 5. Bentuk Gelombang Keluaran Rangkaian Pembangkit Sinyal Gerbang (Singh, 1998)

Sinyal ini didapatkan saat sinyal C dibandingkan dengan variabel tegangan DC pada Gambar 5 bagian D yang membantu komparator $\mathrm{IC}_{4}$. Bentuk gelombang yang didapat terlihat seperti Gambar 5 bagian E yang dibatasi oleh dioda zener, oleh karena itu sinyal cocok dengan TTL. Pulsa pada Gambar 5 bagian $\mathrm{F}$ diumpankan ke monostabil yang memberikan keluaran komplemen pada Gambar 5 bagian $\mathrm{G}$ dan Gambar 5 bagian $\mathrm{H}$. 
Lebar pulsa Gambar 5 bagian G dan Gambar 5 bagian $\mathrm{H}$ diatur dengan jarak 10 mikrodetik. $\mathrm{IC}_{6}$ memiliki dua gerbang input $A N D$. $\mathrm{IC}_{7}$ adalah IC timer yang menghasilkan "gelombang pembawa" (pulsa frekuensi tinggi dengan besarnya frekuensi mencapai $10 \mathrm{kHz}$ ) ditunjukkan Gambar 5 bagian I. Lebar pulsa Gambar 5 bagian $\mathrm{G}$ dan bagian $\mathrm{H}$ masingmasing di-AND-kan dengan frekuensi tinggi, karena itu didapatkan modulasi pulsa pada Gambar 5 bagian G1 dan bagian H1. Transistor T1, T2 bertindak sebagai driver penguat transformator pulsa TR1, TR2. Transformator TR1, TR2 tersebut akan mendrive rangkaian gate-katoda SCR. Pulsa yang didapatkan G1 dan H1 diumpankan ke transistor saklar yang bertindak sebagai penguat. Dioda D1 dan D2 menyilang pada bagian primer transformator pulsa untuk melindungi transistor. Dioda $\mathrm{D}_{4}$ dan $\mathrm{D}_{6}$ pada gate-circuit melindungi $\mathrm{SCR}$ dari voltage reverse yang kembali. Dioda $\mathrm{D}_{3}$ dan $\mathrm{D}_{5}$ mencegah aliran balik arus dari gate selama periode konduksi.

Transformator Pulsa. Transformator pulsa pada dasarnya adalah sebuah transformator dengan pasangan 6 sumber pulsa energi listrik ke beban yang bentuk dan sifatnya tidak berubah. Pulsa dari transformator ini dapat berulang maupun tidak berulang. Transformator pulsa sering digunakan untuk pasangan generator pemicu pulsa dengan thyristor, biasanya untuk mendapatkan isolasi antara dua rangkaian. Transformator pulsa yang biasa digunakan untuk mengontrol SCR adalah dua kumparan dengan perbandingan 1:1 dan tiga kumparan dengan perbandingan 1:1:1. Transformator pulsa yang digunakan pada penelitian ini adalah transformator pulsa kecil yang hanya dapat menghantarkan tegangan kecil pada lebar pulsa pada beberapa mikrodetik. Rangkaian dasar dari transformator pulsa ditunjukkan pada Gambar 6. Sinyal masukan diberi lambang E, Resistor $\mathrm{R}$ berfungsi sebagai pembentuk gelombang sinus dari arus I, dan nilai resistor harus lebih kecil dari impedansi transformator.

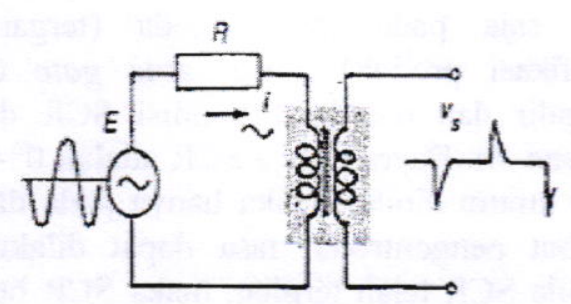

\section{Gambar 6. Rangkaian Dasar \\ Transformator Pulsa (Wasito, 2001)}

Inti transformator adalah material berlamel yang cepat jenuh. Oleh karena itu, bila arus primer mencapai suatu harga, maka medan magnet tidak akan naik lagi. Lilitan sekunder hanya akan terinduksi tegangan jika fluks magnetik berubah. Dan jika fluks magnetik tetap maka tegangan pada lilitan kedua akan berharga nol. Bentuk gelombang keluaran dari transformator pulsa ditunjukkan pada Gambar 7.

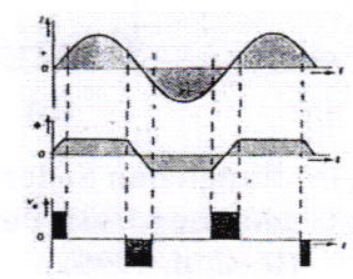

\section{Gambar 7. Bentuk Gelombang Keluaran Transformator Pulsa (Wasito, 2001)}

IC TCA 785. IC TCA 785 merupakan produk dari Siemen Semikonduktor Group yang dibuat untuk menghasilkan pulsa pemicu (trigger pulse) untuk mengontrol fasa pada SCR, triac, dan transistor, antara 0 derajat hingga 180 derajat pada sumber tegangan AC. IC TCA 785 memerlukan sumber tegangan antara 8 Volt hingga 18 Volt, frekuensi kerja $10 \mathrm{~Hz}$ hingga $500 \mathrm{~Hz}$, serta temperatur kerja antara $25^{\circ} \mathrm{C}$ hingga $85^{\circ} \mathrm{C}$. Sinkronisasi sinyal dibutuhkan dengan menggunakan resistansi tingkat tinggi dari tegangan saluran $\left(\mathrm{V}_{\mathrm{s}}\right)$.

IC ini dapat diaplikasikan pada kontrol tegangan AC terkontrol (conventer) satu fasa dan tiga fasa, dan kontrol tegangan DC terkontrol (DC chopper). IC ini memiliki kaki (pin) sejumlah 16. Gambar 8 adalah konfigurasi pin IC TCA 785.

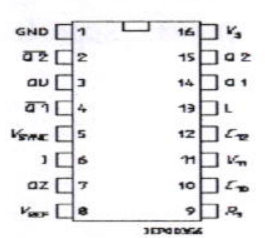

Gambar 8. Konfigurasi Pin IC TCA 785 
Tabel 1. Deskripsi dari Konfigurasi IC TCA 785

\begin{tabular}{|c|c|c|}
\hline PIN & Simbol & Fungsi \\
\hline 1 & GND & Netral (Ground) \\
\hline 2 & Q2 & Keluaran 2 terbalik (Out put 2 inverted) \\
\hline 3 & $\mathrm{QU}$ & Keluaran U \\
\hline 3 & Q2 & Keluaran 1 tebalik (Out put I inverted) \\
\hline 4 & $\mathrm{~V}_{\text {sunc }}$ & Sinkronasi tegangan (Synchronous vollage) \\
\hline 5 & I & Penghalang (Inhibit) \\
\hline 6 & QZ & Keluaran Z (OutputZ) \\
\hline 8 & $\mathrm{~V}_{\mathrm{REF}}$ & Tegangan terstabilkan (Stabilized vollage) \\
\hline 9 & $R_{9}$ & Ramp resistor (Ramp resistance) \\
\hline 10 & $\mathrm{C}_{10}$ & Ramp kapasitor (Ramp capacitance) \\
\hline 11 & $\overline{V_{11}}$ & Kontrol tegangan \\
\hline 12 & $\mathrm{C}_{12}$ & Perpanjangan pulsa (Pulse extension) \\
\hline 13 & $\mathrm{~L}$ & Pulsa perpanjangan (Long pulse) \\
\hline 14 & $\mathrm{Q}_{1}$ & Keluaran 1 (Output I) \\
\hline 15 & $\mathrm{Q}_{2}$ & Keluaran 2 (Output 2) \\
\hline 16 & Vs & Sumber tegangan (Supply voltage) \\
\hline
\end{tabular}

Prinsip kerja IC TCA 785 adalah sinyal sinkronasi dari tegangan sumber dihubungkan pada kaki nomor 5 (VSYNC) melalui resistor berhambatan tinggi. Zero detector akan menentukan letak titik nol dan disimpan ke dalam memori sinkron. Detector ini kemudian akan mengendalikan gelombang tegangan yang sesuai dengan frekuensi sumber tegangan. Kapasitor C10 dan R9 akan menentukan kemiringan dari bentuk gelombang yang dihasilkan. Gelombang ini kemudian dibandingkan dengan tegangan referensi V11 oleh comparator (pembanding). Sinyal ouput dari comparator ini kemudian akan diteruskan ke rangkaian logika. Bila tegangan referensi pada kaki 11 (V11) pada posisi terendah, maka sudut penyulutan akan menunjukkan $\alpha=0$ derajat. Sehingga untuk mengatur sudut pemicuan dapat dilakukan dengan mengatur besar tegangan yang dikirimkan ke pin 11 (V11).

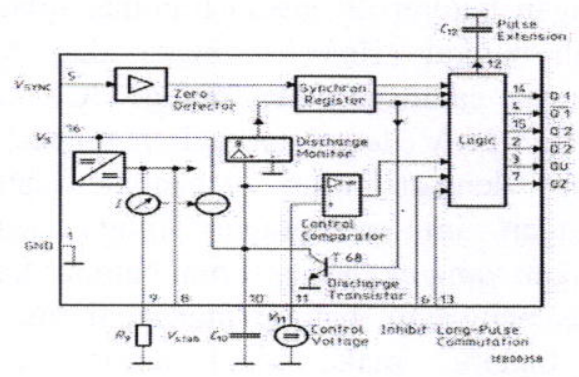

Gambar 9. Prinsip Kerja IC TCA 785

Persamaan yang dapat digunakan untuk mendapatkan sudut pemicuan adalah persamaan berikut :

$$
\alpha=180^{\circ} \times \frac{V_{\text {CONIROI }}}{\hat{V}_{s t}}
$$

dimana:

Vkontrol : tegangan kontrol yang dikirimkan ke pin 11 (V11); Vst : (V10) diatur bernilai 10 Volt, namun lebih tepatnya pengaturan sudut pemicuan dapat dilakukan menggunakan osciloscope, sehingga dapat diperoleh hasil pengukuran yang lebih baik.

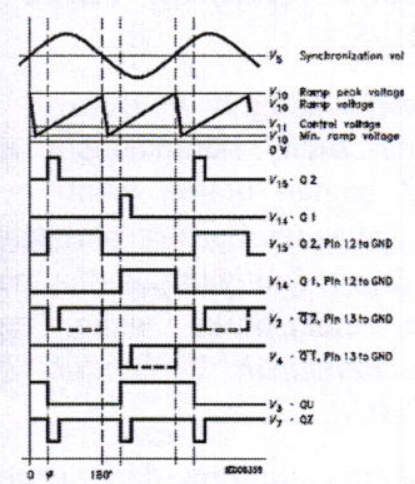

\section{Gambar 10. Gelombang Keluaran IC TCA 785}

Baterai. Jenis baterai yang digunakan pada sistem UPS ini berjenis aki (accumulator) 10 Ah. Baterai ini umumnya mampu menjadi sumber tegangan cadangan maksimal selama 10 jam dengan arus $1 \mathrm{~A}$. Ada beberapa hal yang harus diperhatikan dalam pemakaian baterai untuk memperpanjang siklus hidup baterai adalah sebagai berikut :

a) Deep Of Discharger (DOD), yaitu presentasi dari tegangan pengosongan terhadap tegangan nominal yang diperbolehkan untuk pemakaian baterai.

b) Over Charging (tegangan maksimal pengisian) yaitu presentasi tegangan pengisian terhadap tegangan nominal yang diperbolehkan dalam pengisian baterai.

c) Kapasitas pengisian baterai atau kemampuan arus pengisian yang diperbolehkan untuk pengisian baterai.

d) Kapasitas pengosongan atau kemampuan arus pengosongan yang diperbolehkan untuk pengisian baterai.

\section{PERANCANGAN}

Perancangan penyearah dan $B C R$ bertujuan untuk:

a) Mengetahui pembuatan rangkaian Penyearah Terkendali Penuh dan BCR pada UPS. 
b) Mengetahui pengaruh penggunaan Penyearah Terkendali Penuh untuk charger baterai pada UPS.

c) Mengetahui spesifikasi peralatan yang digunakan untuk membuat rangkaian Penyearah Terkendali Penuh dan BCR.

d) Mengetahui karakteristik dan kinerja Penyearah Terkendali Penuh dan BCR pada UPS.

Pada rancang bangun Penyearah Terkendali Penuh dan $B C R$, perancangan alat dibagi menjadi 2 bagian utama yakni perancangan alat yang pertama berupa perancangan fisik dari alat (box) dan yang kedua perancangan komponen elektronika yang terdiri dari rangkaian Penyarah Terkendali Penuh dan rangkaian $B C R$.

Adapun skema diagram dari sistem UPS itu sendiri dapat dilihat pada Gambar 11.

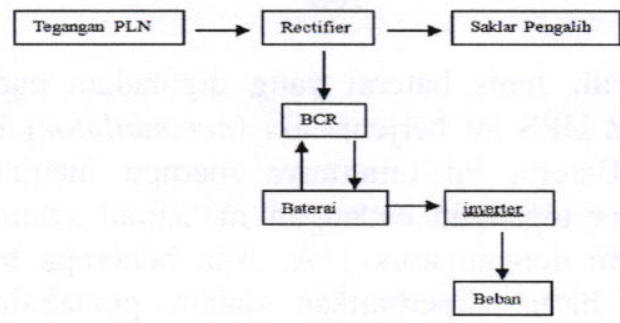

\section{Gambar 11. Skema Diagram UPS (Uninterruptible Power Supply)}

Penyearah Terkendali Penuh. Adapun skema rangkaian perancangan rangkaian penyearah terkendali penuh seperti ditunjukkan pada Gambar 12.

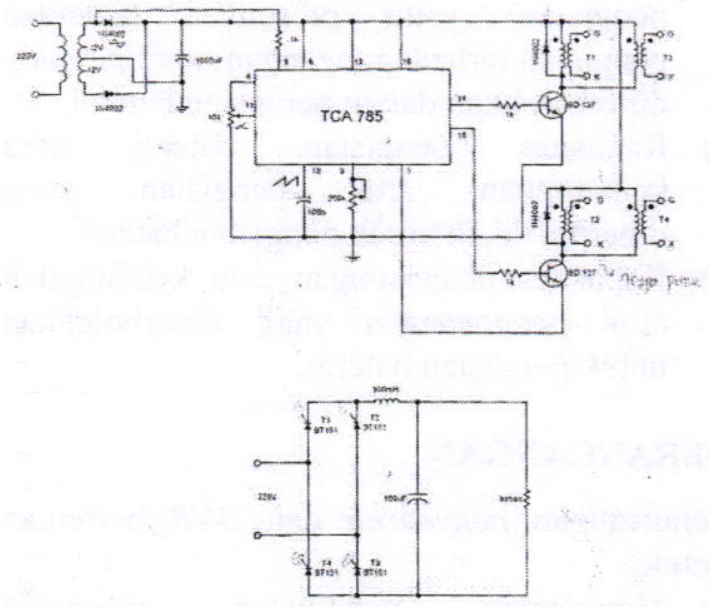

Gambar 12. Penyearah Terkendali Penuh

BCR (Battery Charger Regulator). BCR atau Rangkaian Histerisis Pengatur Siklus
Pengisian Baterai adalah rangkaian komparator tegangan yang dapat membandingkan besar tegangan masukan (Gambar 13). Pada rangkaian BCR ini tegangan referensi input ke baterai dalam rangkaian sebesar 12 Volt. Penggunaan tegangan referensi ini berfungsi untuk menentukan titik mati atas rangkaian bekerja dan titik mati bawah rangkaian bekerja atau lebih dikenal sebagai HVD (High Voltage Disconected) dan LVD (Low Voltage Disconected).

Pada perencanaan penentuan nilai HVD harus sesuai dengan nominal baterai yang terpasang, sedangkan untuk nilai LVD berfungsi sebagai saklar otomatis untuk menghidupkan kinerja rangkaian histerisis. Nilai $\mathrm{V}_{\mathrm{HVD}}$ adalah sebesar $13,5 \mathrm{~V}$, sedangkan untuk nilai $\mathrm{V}_{\mathrm{LVD}}$ sebesar $10,5 \mathrm{~V}$.

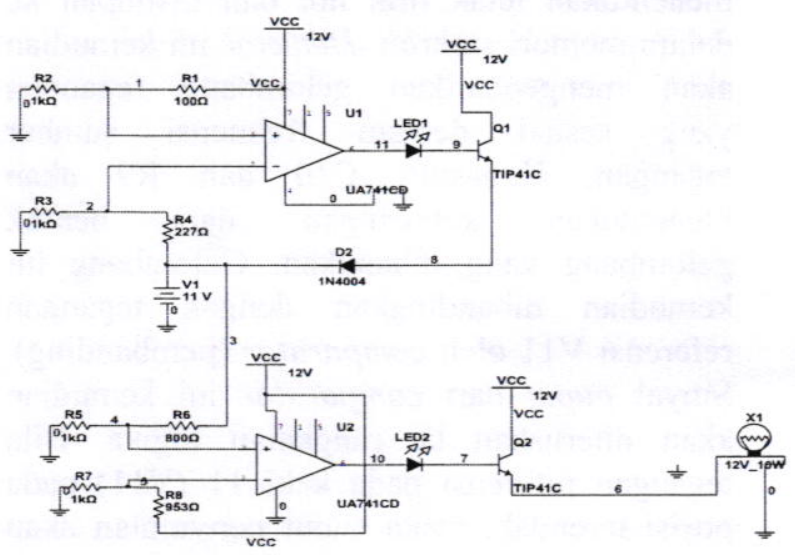

\section{Gambar 13. Rangkaian BCR (Battery Charger Regulator)}

Cara kerja rangkaian di atas adalah pada saat tegangan baterai di bawah nominal nilai titik bawah baterai $(10,5 \mathrm{~V})$, maka akan terjadi tegangan saturasi pada output IC, karena apabila V2 $>$ V1 tegangan pada output IC akan sesuai dengan nilai tegangan saturasi. Tegangan ini mempunyai fungsi sebagai tegangan yang akan mensuplai baterai. Setelah proses pengisian, baterai mencapai titik mati atas baterai, maka akan terjadi $\mathrm{V} 2<\mathrm{V} 1$ sehingga tegangan output pada IC akan berubah menjadi 0 dan akibatnya baterai tidak akan terisi atau terjadi pemutusan suplai terhadap baterai. Pengisian dan pengosongan baterai ini akan terjadi terus menerus terjadi pada nilai tegangan baterai antara $10,5 \mathrm{~V}$ menuju 13,5 V. Kondisi ini diindikasikan oleh lampu LED yang menyala, dan apabila lampu LED mati maka terindikasi bahwa baterai 
sudah mencapai titik mati atas baterai dan terjadi pemutusan pengisian baterai oleh suplai secara otomatis.

\section{HASIL DAN PEMBAHASAN}

Jenis baterai yang digunakan pada rancang bangun penyearah terkendali dan BCR yaitu berjenis akumulator $12 \mathrm{~V}, 10 \mathrm{Ah}$.

Berdasarkan rangkaian pada Gambar 13, data hasil pengamatan pada tanggal 20 Juni 2011, diperlihatkan pada Tabel 2. Pengukuran tegangan dilakukan pada kaki komponen sebelum masuk baterai (+) dan ground (-), sedangkan pengukuran arus dilakukan pada kaki dioda sebelum masuk ke baterai.

Tabel 2. Data Pengujian Kinerja BCR pada Saat Pengisian Baterai

\begin{tabular}{|c|c|c|c|c|}
\hline $\mathbf{V p}(\mathbf{V})$ & $\mathbf{I p}(\mathbf{A})$ & $\mathbf{V b}(\mathbf{V})$ & $\mathbf{T}$ (menit) & $\mathbf{V b}(\mathbf{V})$ \\
\hline 12 & 2.50 & 10.73 & 10 & 10.73 \\
\hline 12 & 2.35 & 10.88 & 20 & 10.88 \\
\hline 12 & 2.05 & 10.99 & 30 & 10.99 \\
\hline 12 & 1.80 & 11.07 & 40 & 11.07 \\
\hline 12 & 1.60 & 11.19 & 50 & 11.19 \\
\hline 12 & 1.45 & 11.35 & 60 & 11.35 \\
\hline 12 & 1.30 & 11.52 & 70 & 11.52 \\
\hline 12 & 1.15 & 11.68 & 80 & 11.68 \\
\hline 12 & 1.00 & 11.72 & 90 & 11.72 \\
\hline 12 & 0.95 & 11.75 & 100 & 11.75 \\
\hline 12 & 0.80 & 11.79 & 110 & 11.79 \\
\hline 12 & 0.75 & 11.82 & 120 & 11.82 \\
\hline 12 & 0.65 & 11.84 & 130 & 11.84 \\
\hline 12 & 0.60 & 11.87 & 140 & 11.87 \\
\hline 12 & 0.55 & 11.89 & 150 & 11.89 \\
\hline 12 & 0.50 & 11.90 & 160 & 11.90 \\
\hline 12 & 0.45 & 11.92 & 170 & 11.92 \\
\hline 12 & 0.40 & 11.93 & 180 & 11.93 \\
\hline 12 & 0.35 & 11.94 & 190 & 11.94 \\
\hline 12 & 0.30 & 11.96 & 200 & 11.96 \\
\hline 12 & 0.25 & 11.97 & 210 & 11.97 \\
\hline 12 & 0.20 & 11.98 & 220 & 11.98 \\
\hline
\end{tabular}

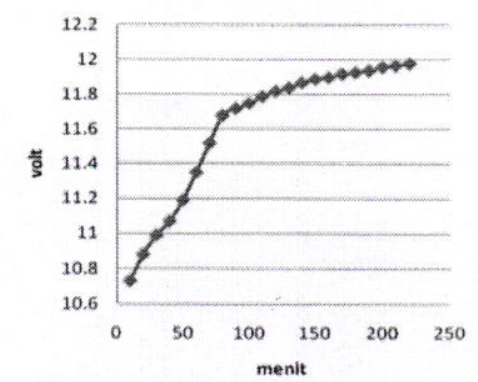

\section{Gambar 15. Grafik Pengisian Baterai}

Gambar 15 menunjukkan karakteristik pengisian pada baterai $5 \mathrm{Ah}$. Dengan menggunakan rangkaian $\mathrm{BCR}$ ini maka didapatkan tegangan pengisian yang cukup stabil, yaitu 12 Volt dengan lama pengisian sekitar 3 jam 40 menit ( \pm 4 jam ).

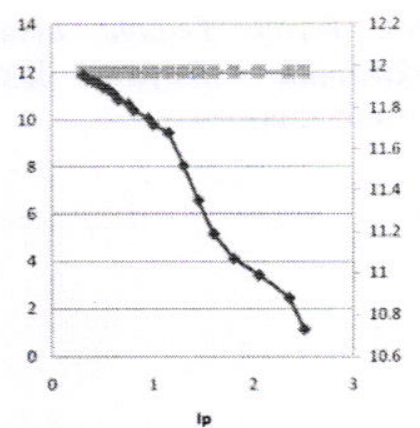

\section{Gambar 16. Grafik Pengujian Kinerja BCR pada Saat Pengisian Baterai}

Dari data pengujian (Gambar 16) dapat dijelaskan bahwa BCR bekerja dengan baik pada saat pengisian. Pada saat awal pengisian, baterai dalam keadaan kosong dan lampu indikator pun menyala, yang menandakan baterai terisi dengan baik. Pada saat pengujian data diambil setiap 10 menit sekali. Perubahan yang terjadi pada tegangan dan arus tidak mengalami perubahan yang signifikan dan relatif konstan. Arus yang terukur pada setiap pertambahan waktu, nilainya semakin kecil. Itu menandakan bahwa baterai mulai penuh terisi. Lampu indikator pada BCR mulai redup pada menit ke 200 dan pada menit ke 220 lampu indikator mati. Hal ini menandakan bahwa baterai telah terisi penuh.

\section{KESIMPULAN}

- Penggunaan penyearah terkendali penuh pada sistem UPS berfungsi mengubah tegangan AC dari sumber (PLN) menjadi DC yang keluarannya dapat diatur dari $0-12$ Volt untuk selanjutnya menjadi input pada rangkaian BCR.

- BCR berfungsi sebagai penghubung dan pemutus arus pengisian baterai 12 Volt. Titik LVD pada rangkaian ini sebesar 10,5 V sedangkan titik HVD sebesar 13,5 V. Lama pengisian pada baterai sekitar 3 jam 40 menit.

\section{DAFTAR PUSTAKA}

Malvino, Albert Poul. 1984. Prinsip-Prinsip

Elekronika.Jakarta:Erlangga.

Sutanto, Ir.Jusmin. 2005. Pengantar Elektronika Daya. Bandung: Politeknik Negeri Bandung, Jurusan Teknik Energi.

Rasid, Warsito, 2001

Singh, 1998 
Zuhal. 1995. Dasar Tenaga Listrik Dan Elektronika Daya. Jakarta : PT.Gramedia. http://www.nubielab.com. Detector dan Kontrol IC TCA 785. - discovering the art and technology.

www.datasheetcatalog.com 